\title{
Service Quality Assessment of Higher Education by Gray Approach (The Case of Kerbala University)
}

\author{
Nawal Mousa Almeyali ${ }^{1}$, Ali Al Mousawi ${ }^{2}$ \\ ${ }^{1} B S c, M S c$, Quality Assurance Unit-College of Medicine-University of Kerbala, ${ }^{2}$ MBChB, MSc. In Community \\ Medicine Assistant Professor at the Department of Family and Community Medicine-College of Medicine- \\ University of Kerbala
}

\begin{abstract}
The quality of higher education has become one of the main challenges facing educational systems in the last two decades. The promotion of services in the field of education and scientific research require active management that continuously improves academic services.

In this study, after identifying the indicators of the quality of higher education services, a questionnaire was distributed to 15 experts in order to elite the quality of higher education services in the university to assess these indicators and select the best effective ones. Then, a second questionnaire was provided to eight experts to evaluate the performance and the weight of these criteria in the university by using Gray weights.

The result of research revealed that the staff has the highest score and the university has a solid foundation. In order to reduce the existing gap, relevant academic subjects related to the disciplines need to be provided. Access to administrative services was improved, as well as electronic office services tailored to students' needs. In order to reduce the gap created for the environmental index, wider green space need to be developed within the university and increasing the opportunity for free web access and free access to valid and up-todate scientific resources are needed.
\end{abstract}

Keywords: Service Quality, Higher Education, Gray Weighting, University of Kerbala. Introduction.

\section{Introduction}

We live in the Information Age characterized by the emergence of modern information and communication technologies ${ }^{(1)}$. The educational system in every country is one of the most complicated social, economic and cultural sub-systems, and is considered as an influential factor in the realization of national macro policies. Considering the wide expansion of educational system activities, qualitative management of the educational system can play an important role in providing better institute's quality of education (Bazargan, 2015) $)^{(2)}$. On the other hand, higher education is a source for inspiration and form the foundation for the development and advancement of any society ${ }^{(3)}$.

To reach the goal of effective education in any educational institution; it is essential to establish an efficient teaching-learning process which could be comprehensively assessed in a framework of an effective behavioral system ${ }^{(4)}$. For this reason the higher education systems in most countries in the world have established a quality management system in order to pay more attention to the quality of education, in addition to improving research and supplying of specialized services. The identification and evaluation an appropriate framework for managing the quality of higher education is one of the requirements for the success of higher education institutions for sustainability, advancement and growth.

The higher education system as a part of every country's educational system plays a critical and essential role in the development of various dimensions of economic and social and cultural development ${ }^{(3)}$. Indeed; the growth and development of all systems in the society are dependent on the development of quantitative and qualitative dimensions of its higher education. In other words, the growth and development 
of countries are tied to their educational system. Graduates of universities are responsible for government and society leading, cultural empowerment, originality, innovation, modern technology management, industry, trading and national security of a country. In the present era, the attention of the people and especially, the youth towards the educational system has been significantly increased. This is accompanied by an increase in the output expectations of the people from these institutions. Therefore, universities, on one side, should improve the quality of their services and on the other side, should have a continuous evaluating and observing system. Such body or system can monitor their current status and make plan for future improvements in these organizations. In the event of any problem; lack of a performance assessing system means losing links with the internal and external factors of the organization that are very important predictors of optimal performance. Indeed, the results of this performance assessment will be an improvement in the organization's activities since the organization cannot function without identifying the challenges and weaknesses that need rapid improvement ${ }^{(5-7)}$.

In recent decades, the higher education system faces significant issues due to the growth of the technical procedure, wide-ranging social, economic and cultural changes and the urgent need for meeting the expanding needs of the community. A meta-synthesis approach was tried to designing a conceptual framework had concluded that out of 52 papers only 42 of them have mentioned codes and factors relevant to the infrastructure ${ }^{(8)}$.

The assessment of quality techniques for identification of the differences and similarities surrounding quality improvement efforts covers each of three service areas typically found in higher education: academic, administrative, and auxiliary functions ${ }^{(9)}$. To assess the quality of services, Shick and Partners (2007) have designed aDeep Learning Skoval model(D.L. Skoval model) based on the combination of models of SERVQUAL and E.S.Q. The designed model has 12 indices: reliability, accountability, trust, empathy, merit, politeness, availability, efficiency, security, flexibility and communication. The Institute of Higher Education for Politics in Washington, DC, has conducted comprehensive studies in guaranteeing quality. Their research results in 2009 showed that organizational support, course development, teaching/Learning, course structure, students support, faculty support, evaluation and valuation are the essential factors in ensuring learning organization ${ }^{(7)}$. Many external studies in the field of multi-criteria decision making have been done to deal with the ambiguity of judgment. Several effective phase models and linear programming models have been presented. However, in recent years, after the presentation of the theory of Gray system by Deng and despite this theory being young and new, it has been used to find the solution for the problems in various fields of science, especially in regards of modeling, prediction, Gray relation analysis, and Gray decision making.

In most cases where the goal is choosing the preferred option and ranking options in uncertain conditions, Gray decision making has been used as a powerful method. Other foreign backgrounds are listed in the table below. In this table, in addition to the author and year of research, the studied university and results of the research are also presented. In Gray relational analysis method analysis method depends on Gray system theory ${ }^{(10)}$. According to the similarity or difference of the developmental trend among the factors, it could measure the relevancy among factors"Gray relevancy". The Gray relational analysis method could be used to describe the relative changes among factors in the system development process. If the relative changes of the two were basically the same in the development process, we could consider the relevancy between them is large, while, conversely, the relevancy is small. In the real world, the relevancy among many factors is Gray, namely the overall information and mutual relevancy is 'indefinite". Therefore, when analyzing the relationship between two factors, we could apply the concept of relevancy to measure the relation between each factor and describe their relative changes quantitatively.

Ghasemi and Ahmadi (2013)(11), Evaluated Higher Education Institutes Performance in Zanjan province by BSC and GAHP. They used a new model is implemented for ranking the institutes. The research population includes 21 faculty members selected by random sampling. 3 separate questioners collected data, analysed by SPSS software, and weighted by Team Expert Choice software. The results of this research showed that in nonprofit institutes of higher education, the most important criteria include higher income, reliability and number of students accepted for higher education.

Recently Ghasemi and Alizadeh (2017) use GMCDM technique to assess antifragility's performance of Iran Banknote papers. Table 1 summarised mentioned research $^{(12)}$. 
Table 1: Summary of research background

\begin{tabular}{|c|c|c|c|}
\hline Author & Year & University & Goal and model used \\
\hline $\begin{array}{l}\text { Owlia and Aspinall } \\
\text { (13) }\end{array}$ & 1996 & Birmingham university & $\begin{array}{l}\text { They presented a new framework for the dimensions of the quality of } \\
\text { higher education services. }\end{array}$ \\
\hline Waugh ${ }^{(14)}$ & 2002 & $\begin{array}{l}\text { Administrative quality } \\
\text { in Australia. }\end{array}$ & He suggested a model for the University's administrative quality. \\
\hline Lalovic $^{(15)}$ & 2002 & The Belgrade university & He presented an evaluation model using the Six Sigma methodology. \\
\hline $\begin{array}{l}\text { Lagrosen, Hashemi, } \\
\text { and Leitner }{ }^{(16)}\end{array}$ & 2004 & $\begin{array}{l}\text { University of Australia } \\
\text { and Sweden }\end{array}$ & $\begin{array}{l}\text { They evaluated dimensions of service quality in higher education } \\
\text { institutions and compared these dimensions. }\end{array}$ \\
\hline $\begin{array}{l}\text { Yang, Yan-ping, and } \\
\text { Jie }^{(17)}\end{array}$ & 2006 & China Higher education & $\begin{array}{l}\text { They studied two. They suggested a suitable model for evaluating the } \\
\text { quality of service in China using the SERVQUAL model. }\end{array}$ \\
\hline Tsinidou $^{(18)}$ & 2010 & Turkey & $\begin{array}{l}\text { They studied two universities in Turkey and concluded that students care } \\
\text { most about the two dimensions of empathy and quality of service. }\end{array}$ \\
\hline Noaman $^{(19)}$ & 2010 & $\begin{array}{l}\text { Higher education } \\
\text { institutes in Greece }\end{array}$ & Decision-makers in higher education service quality were identified. \\
\hline $\begin{array}{l}\text { Ghasemi and } \\
\operatorname{Ahmadi}^{(11)}\end{array}$ & 2013 & $\begin{array}{l}\text { Nonprofit Higher } \\
\text { education institutes in } \\
\text { Zanjanprovince (Iran) }\end{array}$ & $\begin{array}{l}\text { Evaluation of Higher Education Institutes Performance by BSC and } \\
\text { GAHP }\end{array}$ \\
\hline $\begin{array}{l}\text { Ghasemi and } \\
\text { Alizadeh (12) }\end{array}$ & 2017 & $\begin{array}{l}\text { Antifragility } \\
\text { Assessment }\end{array}$ & $\begin{array}{l}\text { Application of Gray MCDM to antifragility assessment of Iranian } \\
\text { Banknote papers. }\end{array}$ \\
\hline
\end{tabular}

Source: Noaman, Amin Yet al. (2014) ${ }^{(19)}$

The literature review showed only few studies in Iraq evaluated the service quality in higher education. A study assessing the private open university in a study in a tourism college in Mosul in 2007 reported that technical and administrative level was low ${ }^{(20)}$. While a more recent study in the College of Tourism Sciences concluded that there is a kind of good performance related for the organization, planning and evaluation, and support for users, but there is a Kind of average performance related to resources and facilities ${ }^{(21)}$. Another study in the Administration and Economics College at the university of Anbar concluded that the quality team lacks accountant of quality costs which made a weak in detailed documentation of quality costs ${ }^{(22)}$. While a study in Baghdad University tried to determine the links between strategic planning and entrepreneurial quality through a survey among 65 academic staff in three faculties concluded that a significant association was found $^{(23)}$. Additionally, a study in Dewaniyah Technical Institute concluded that building a knowledge Society is fundamental point for students satisfaction ${ }^{(24)}$.

\section{Methodology}

Tsinidou, Noaman, Ragab, Madbouly, Khedra and Fayoumi ${ }^{(18)}$, in their research titled "Higher Educational Quality Assesment Model to achieve educational quality standards " at King Abdulaziz University (Saudi Arabia) presented HEQAM model for improving academic services. This model has eight main dimensions (curriculum, academic staff, business perspective, infrastructure, e-services, library services, office services and environments).

\section{Research Methodology:}

\section{Method of data collection}

The most important method of data collection in this study were as follows:

1. Library study: In this field to collect information in theoretical Foundations and topic research literature; library resources, articles, books and the internet have been used.

2. Field researches: In this section, a questionnaire was used to collect data and information for analysis. The questionnaire is a highly structured technique for collecting data, in which for each answer the same set of questions are asked. The mentioned questionnaire includes:

(a) General questions: In general questions, the attempted concentrates on collecting project- 
doers' profile, general and demographic information of respondents.

(b) Particular questions: This section contains 57 questions related to various factors adapted to the literature of the subject. When designing this section, questions have been tried to be as short as possible, hence easily understood, and to avoid asking negative questions. To design this section, the 5-option Likert spectrum has been used, which is one of the most common measurement scales.

Table 2: The questionnaire preparation guide

\begin{tabular}{|l|l|l|}
\hline Factor name & Number of questions & Reference \\
\hline Educational program & 6 Questions & SERVQUAL (Parasuraman et al. ), 1985) \\
\hline Staff & 11 Questions & SERVQUAL (Parasuraman et al. ), 1985) \\
\hline Infrastructures & 7 Questions & $\begin{array}{l}\text { SERVPERF (Cronin and Taylor, 1992) and SERVQUAL (Parasuraman et al., } \\
1985)^{(25)}\end{array}$ \\
\hline Environment & 6 Questions & HEdPERF (Abdullah, Firdaus 2006) \\
\hline Office services & 10 Questions & Noaman, Amin Yet al. (2014)(19) \\
\hline Library services & 6 Questions & HEdPERF (Abdullah, Firdaus, 2006) \\
\hline Electronic services & 5 Questions & HEdPERF (Abdullah, Firdaus, 2006) $)^{(27)}$ \\
\hline Job perspectives & 6 Questions & Noaman, Amin Y et al. (2014) $)^{(19)}$ \\
\hline
\end{tabular}

In each research, various stages are gone through. In many books, a precise number of research steps have been mentioned, such as the formulation and clarification of an issue or a topic, literature review, research design, data collection, data analysis, and writing. However, Sanders and colleagues (2009) ${ }^{(28)}$, believe in rare cases, all of these steps happen in a row, without going back to the previous stages. In reality, we may want to go back to the previous stages and review our operations. Every time previous stages are rectified, the idea of research slightly changes, and this change is reflected in all stages of the research. However, in this research, it has been attempted to do the research process in a reasonable order.

After preparing a long list of criteria, it is the time for their refinement and screening. The reason for this is the high number of extracted criteria, preventing the possible reduction of the accuracy in completing questionnaires related to the weight of selected criteria, and the likelihood of an increase in inconsistency rates in experts responses. Screening of the extracted criteria was done by using a survey on experts about determining the most important criteria affecting the quality of education services according to a Likert spectrum. In order to have the necessary validity for this questionnaire, it was attempted to avoid using complex phrases as far as possible. To assess the reliability of this questionnaire, the Cronbach Alpha has been used. The estimated value of this index for the whole questionnaire was 0.927 .

Then, after collecting completed questionnaires and in order to distinguish criteria with a higher degree of significance, the binomial test (sometimes called the ratio test) was used.

The assumptions of the mentioned test are as follows, in which the null hypothesis $\left(\mathrm{H}_{0}\right)$ which expresses the lack of effect for the variable and an alternative hypothesis $\left(\mathrm{H}_{1}\right)$ which expresses the presence of effect for the variable.

\section{Equation 1:}

$$
\left\{\begin{array}{l}
H_{0}: P=P_{0} \\
H_{1}: P \neq P_{0}
\end{array}\right.
$$

After distributing the questionnaire and collecting information through the binomial test (ratio), the most critical indices were extracted and became the base of the research. Giving Weight to the criteria using the Gray method

During the initial step, the analysis process was formulated by a group of eight specialists in a targeted manner with already-mentioned explanations. These specialists answered the questionnaire related to 
identifying eight qualitative components that resulted in the presentation of 28 characteristics in the university.

Choosing approximate language terms for evaluating performance rate and weight of the importance of qualitative characteristics

To help professionals while allocating the performance rate of qualitative characteristics; linguistic terms in Likert scale were chosen as Excellent, very good, good, fair, poor, very poor, worst. In order to assess the importance of weighting the qualitative characteristics, linguistic terms have been chosen as very high, high, fairly high, medium, relatively low, low, very low. The Gray triangular used numbers along with the linguistic variables during the research to facilitate analysis (Table 3).

Table 3: The linguist terms and its peer Gray numbers

\begin{tabular}{|l|c|c|c|}
\hline Language terms & Gray numbers & Language terms & Gray numbers \\
\hline The worst (w) & $(0-1.5)$ & Very Low (VL) & $(0-0.15)$ \\
\hline Very weak (vp) & $(1-3)$ & Low (l) & $(0.1-0.3)$ \\
\hline Fair (f) & $(3-7)$ & Medium (m) & $(0.3-0.7)$ \\
\hline Very good (vg) & $(7-9)$ & High (h) & $(0.7-0.9)$ \\
\hline Excellent (e) & $(8.5-10)$ & Very High (vh) & $(0.85-1)$ \\
\hline
\end{tabular}

Linguistic terms and synonyms Gray numbers (peerto-peer) have been adapted by previously-performed studies about performance assessment related to qualitative assessment and was confirmed by the experts.

Assessing the importance of gray weight of quality characteristic: According to the following table, the weight of the lower and upper limit of the qualitative characteristics for each variable has been for Educational program, Staff, Infrastructure, Environment, Office services, Library services, Electronic services and Job perspectives: 0.894, 1, 0.832, 0.949, 0.982, $0.989,0.892,0.915$, respectively. The highest weight is for the staff criterion (6.85-8.95), and the rest of the criteria have been normalized. It seems that the staff in the university, in terms of experts and quality specialists, had acceptable performance. The lowest weight was assigned to the university infrastructure criterion (2.585.41). The other criteria were: educational program (3.72-6.81), environment (4.81-7.00), office services (4.75-7.58), library services (5.56-8.43), electronic services (4.88-7.12) and job perspectives (4.15-7.06).

Performance rate of qualitative characteristics: A detailed assessment of the expert assessment of the qualitative characteristics showed that very good (VG) assessment formed the majority of answers $(\%, 23$ Out of 40 , table 4 ).

Table 4: Details of the expert assessment of the qualitative characteristics Integration of Gray rates and weights

\begin{tabular}{|c|c|c|c|c|c|c|c|c|}
\hline \multirow{2}{*}{ Qualitative Characteristics } & \multicolumn{8}{|c|}{ Experts evaluation } \\
\hline & E1 & $\mathbf{E 2}$ & $\mathbf{E 3}$ & E4 & $\mathbf{E 5}$ & E6 & E7 & $\mathbf{E 8}$ \\
\hline Curriculum provides appropriate scientific subjects. & VG & VG & $\mathrm{VP}$ & VP & $\mathrm{F}$ & VG & $\mathrm{E}$ & $\mathrm{F}$ \\
\hline The curriculum includes specialized courses (software education). & $\mathrm{F}$ & $\mathrm{F}$ & VP & $\mathrm{E}$ & $\mathrm{F}$ & $\mathrm{F}$ & $\mathrm{F}$ & $\mathrm{F}$ \\
\hline University staff never turn down students' requests to cooperate & $\mathrm{F}$ & $\mathrm{F}$ & VG & VG & $\mathrm{E}$ & VG & $\mathrm{E}$ & VG \\
\hline Staff have a good relationship with students. & VG & VG & $\mathrm{E}$ & VG & VG & VG & VG & VG \\
\hline University staff spend adequate time to consults with students & VG & $\mathrm{F}$ & VG & VG & VG & VG & VG & VG \\
\hline
\end{tabular}


The arithmetic means, mode and median are method that are adapted to integrate multiple decision-makers assessments. The arithmetic mean due to its widespread use, have been used for research to integrate and unify comments, during the research. During the research, the arithmetic mean of Gray performance rate and arithmetic mean of performance rate for each characteristic has been determined by $\mathrm{Rj}$ and $\mathrm{Wj}$ symbols. Calculation of $\mathrm{Rj}$ and $\mathrm{Wj}$ through equation 1 and 2 :

\section{Equation 1:}

$$
\boldsymbol{R}_{j}=\left(\boldsymbol{a}_{j} \bullet c_{j}\right)=\frac{R_{j 1}+R_{j 2}+\cdots+R_{j m}}{m}
$$

\section{Equation 2:}

$$
w_{j}=\left(x_{j} Z_{j}\right)=\frac{w_{j 1}+w_{j 2}+\cdots+w_{j m}}{m}
$$

In order to unify and consolidate the Gray rates and the Gray weights used to determine the overall qualitative Gray index equation three have been used:

\section{Equation 3:}

$$
\mathrm{GQI}=\frac{\sum_{j=1}^{n} w_{j} \times R_{j}}{\sum_{j=1}^{n} w_{j}}
$$

For example, the two qualitative characteristics of the curriculum and staff are calculated as follows:

\section{Curriculum Characteristic:}

$$
\left\{\begin{array}{l}
R_{j}=(6.81 ، 3.71) \\
w_{j}=(0.93 ، 0.74)
\end{array}\right.
$$

\section{Staff Characteristic:}

$$
\left\{\begin{array}{l}
R_{j}=(8.95 ، 6.85) \\
w_{j}=(0.94 \times 0.75)
\end{array}\right.
$$

As a result, the integrated Gray index for two characteristics is calculated as follows:

$\frac{\sum_{j=1}^{n} w_{j} \times R_{j}}{\sum_{j=1}^{n} w_{j}}=\frac{\{=(6.81 \cdot 3.71) \times(0.93 \cdot 0.74)\}+\{(8.95 \cdot 6.85) \times(0.94 \cdot 0.75)\}}{(0.93 \cdot 0.74)+(0.94 \cdot 0.75)}$

Similarly, the integrated Gray index for all indices is calculated as a general index. After calculating the whole performance rate average and the arithmetic mean of Gray weights for all characteristics, according to equation three the general integrated Gray quality index (GQI) of qualitative characteristic is $\mathrm{GQI}=(4.80,7.33)$.

\section{Conclusion}

Determining the Euclidean Distance to Adapt to Approximate Level of Quality: When the Gray quality index is obtained, it should be adapted to the language and verbal terms in order to determine the amount of quality level. During this study, the Euclidean distance method will be used for this purpose, since this is the best and most intuitive and understandable way for humans. In this study, linguistic expressions such as, Extremely Quality, Very Quality, Quality, Fairly Quality, Slowly Becoming Quality have been used in order to adapt and determine the quality level. Linguistic expressions and corresponding Gray numbers are given below:

Extremely Quality $(\mathrm{EQ})=(8.5-10)$

Very Quality $(\mathrm{VQ})=(5.5-8.5)$

Quality $(\mathrm{Q})=(3.5-5.5)$

Fairly Quality $(\mathrm{FQ})=(1.5-3.5)$

Slowly Becoming Quality $(\mathrm{SQ})=(0-1.5)$

Then Euclidean distance is calculated as follows:

$$
D=\sqrt{\left\{\sum\left(f_{F A I}(x)-f_{A L_{i}}(x)\right)^{2}\right\}}
$$

$\mathrm{D}(\mathrm{FA}, \mathrm{EQ})=4.556601$

$\mathrm{D}(\mathrm{FA}, \mathrm{FQ})=5.061145$

D(FA, VQ) $=1.3585$. $\mathrm{D}(\mathrm{FA}, \mathrm{Q})=2.2499$

$\mathrm{D}(\mathrm{FA}, \mathrm{Q})=7.537464$

By comparing the values of the calculated Euclidean distances, it is observed that the lowest Euclidean distance is related to the Very Quality level; resultantly the qualitative performance level of the university is Very Quality level (VQ).

After Euclidean calculations of each criterion, the final result categorized based on indices is presented in table 7. According to the table below, most of the indices have a desirable quality in the studied university.

Infrastructure, environment and career prospects indices have lower quality in comparison with other indices. Therefore, quality improvement programs in these indices should be prioritized by university officials. The results showed that the Educational program, Staff, Infrastructure, Office services, Library services, Electronic services were in "very quality", 
while was in "Satisfying quality" for Environment and job Perspectives.

As expected from the comparison of the status quo and desirable situation of quality of higher education services criteria, there is a significant gap between some criteria. This Figure has been presented below.
As mentioned beforehand, for assessing the quality of higher education services, eight indices at the current level and desirable level were evaluated among eight academic experts through a questionnaire approach. For calculating the importance of the main indices, the given points of sub-indices were averaged. Moreover, to reach a better analysis, all collected data were normalized and then analyzed.

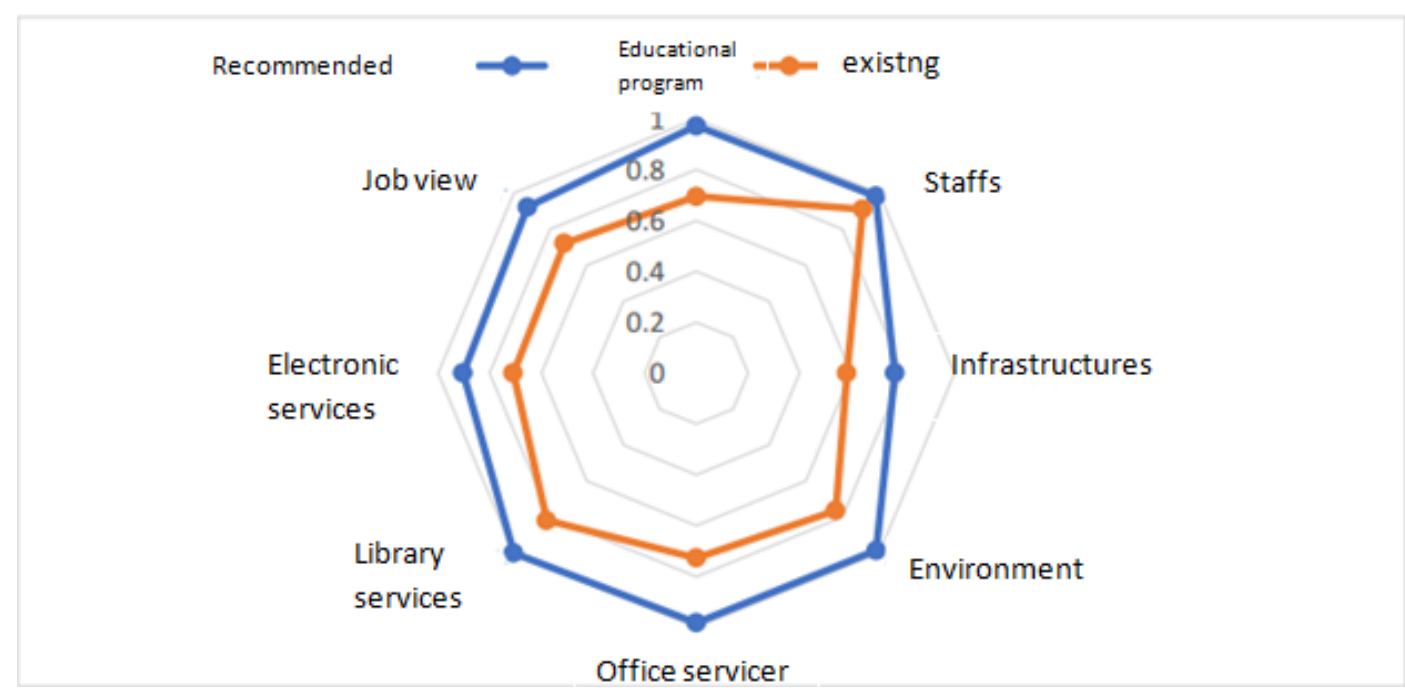

Figure 1: Comparison between existing status and recommended status of higher education services quality dimensions

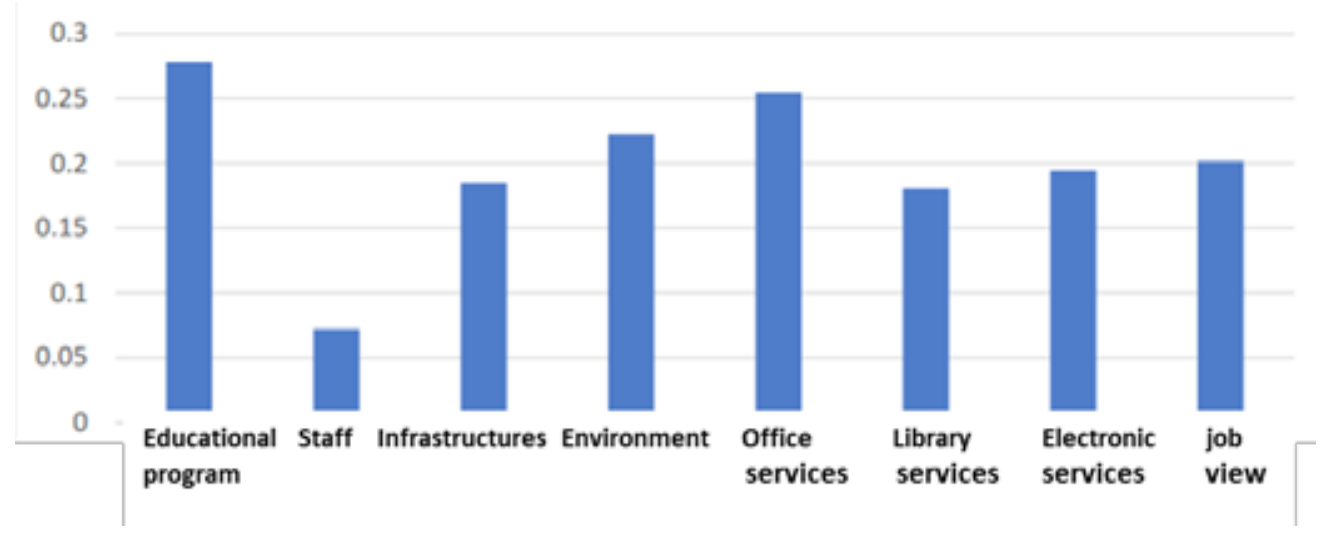

Figure 2: The rate of guff in existing weights of quality dimensions in Kerbala university higher education services

With a slight reflection in comparison of the current and desired weights, it can be understood that the lowest gap in staff index and the highest gap is in the university's curriculum index. For a better analysis of the gap in weights of each criterion, the bar chart (Figure 2) is presented:
According to Figure 1 and by comparing the current and desired weights, it can be concluded that the lowest gap is staff index. In other words, it can be said that from the viewpoint of specialists and experts of the quality of Kerbala University, staff have performed their duties correctly and have the necessary commitment to perform their duties. Therefore, there is not a noticeable gap in this criterion. 


\section{Results}

1. It seems that considering achieved quality dimensions in this study can be used in assessing the quality of academic services. The results of the present study indicates that management process quality of departments at the university is rather desirable and requires planning its improvement

2. Looking at the obtained weights in the table showed that the staff have the highest weight. This means that the performance of the staff in the studied university is within acceptable limits. For this purpose, to maintain the status quo, an appropriate reward system can be established for the staff in the university.

3. Library services are ranked second. However, it could be understood that the provided library services at the university, as well as staff services, have a satisfactory level.

4. University environment: Due to the gap between the status quo and the desired situation, it is recommended to improve the available commuting services (such as provision of transportation services, precise timing and scheduling for commuting according to the peak hours of students attendance and improvement of covered routes in different spots of town), or partially, in routes where coverage of services is not possible. The cost of students' commute is partially paid by the student. Moreover, the development of parks and green spaces are also proposed due to the lack of enough space for the students.

5. Administrative and electronic services: According to Figure 2, the university situation in this criterion is far from being desired, and it is suggested that, in order to reduce the gap between the current and desirable status of this criterion, the administrative processes of the university should be clearly explained to freshmen. In addition, reviewing the administrative processes will provide students with fast, efficient and accurate services. Also, to facilitate the use of these services and access to them for students; it is necessary to synchronize the hours of administrative services with hours of student attendance at the university. Due to the nature of the administrative service; these services should be provided electronically with appropriate technical support to avoid loss of time and money. Also, appropriate communication tools (such as telephone operators) should be used to address student problems in different service units.

6. Library Services: To overcome the gap between the status quo and the desirable condition in this criterion, the university is recommended to update bookshelves and add books published in recent years to the shelves. Necessary facilities for students to access to new profiles and valid journals should be provided. Development of electronic library services (such as the extension of fines payment for late delivery of books and others). Considering copyright law, an e-book sharing network for students should be followed. Also, selecting the right place (that has enough lighting, internet access, providing reading equipment, and others) of the library for students to study.

7. Career perspective: To bridge the gap between the current situation and the desired situation in this criterion, it is suggested that a unit called "Relationships with Business" should be established that allows students to get acquainted with different occupational fields and get familiar with new job titles and opportunities. Also, negotiating with foreign universities provide students with the opportunity to continue studying abroad. A road map for different fields should be providing to make clear to students their career perspectives.

8. Curriculum: According to Figure 2, the biggest gap between the current and desired status is in this criterion. Therefore, it is suggested that firstly a good academic program should be provided; secondly, by offering special courses (including upto-date software training programs), they improve this important dimension. (To any one to five) . Also, given the assigned weight to each criterion (Table1), this one has a good weight.

9. Staff: This qualitative dimension has the lowest between the current and the desired status. Also, the assigned weight for this criterion is the highest. Therefore, university authorities are suggested to set up a rewarding system proportionate to staff's performance and by providing better facilities, they try to maintain the status quo or even improve it.

10. Infrastructure: This criterion has attained the lowest weight. It seems that the university did not perform well in providing infrastructure and electronic services, including well-equipped buildings, green Service quality assessment in higher education, 
and the case of Technological Educational Institute (TEI), Greece. In 9th International Conference on Marketing and Development: Marketing Contributions to Prosperity and Peace (pp. 8-11). spaces, sports facilities, well-equipped classrooms and laboratories, and medical facilities. Also, the gap between the existing and desirable situation of these dimensions are almost equal and worth pondering. Therefore, it is recommended that the university officials improve the existing situation by improving the university's infrastructure facilities (including building well-equipped buildings and laboratories, providing appropriate treatment facilities, expansion internet services, and others).

Ethical Clearance: Taken from Kerbala Medical College ethical committee

Source of Funding: Self funds

Conflict of Interest: None

\section{References}

1. Alcácer J, Cantwell J, Piscitello L. Internationalization in the information age: A new era for places, firms, and international business networks? : Springer; 2016.

2. Bazargan A. Educational evaluation concepts, models and operational processes. Tehran: SAMT Publishers. 2001.

3. Irby DM, Cooke M, O'Brien BC. Calls for reform of medical education by the Carnegie Foundation for the Advancement of Teaching: 1910 and 2010. Academic Medicine. 2010;85(2):220-7.

4. Zeithaml V, Bitner M, Gremler D. Services Marketing McGraw Hill. New York. 1996.

5. Rezaeian N, Shirvanizadeh N, Mohammadi S, Nikkhah M, Arab SS. The inhibitory effects of biomimetically designed peptides on $\alpha$-synuclein aggregation. Archives of biochemistry and biophysics. 2017;634:96-106.

6. Brown Jr J. Assessment matters in higher education: McGraw-Hill Education (UK); 1999.

7. Sharaf M, Mirzaei Karzan A, Mazbuhi S. Internal Evaluation in the Higher Education System: A Case Study in Iran. Journal of Research in Educational System.5(14):147-67.

8. Dokouhaki H, Zarifsanaiey M, Zarifsanaiey N. A Meta-Synthesis Approach to Designing a
Conceptual Framework for Mobile Learning in Higher Education. 2019:1-13.

9. Quinn A, Lemay G, Larsen P, Johnson DM. Service quality in higher education. Total Quality Management. 2009;20(2):139-52.

10. Julong D. Introduction to grey system theory. The Journal of grey system. 1989;1(1):1-24.

11. Ghasemi AR, Ahmadi SH. The Evaluation of Higher Education Institutes Performance by BSC and GAHP. 2013.

12. Ghasemi A, Alizadeh M. Evaluating organizational antifragility via fuzzy logic. The case of an Iranian company producing banknotes and security paper. Operations Research and Decisions. 2017;27(2):2143.

13. Owlia MS, Aspinwall EM. A framework for measuring quality in engineering education. Total Quality Management. 1998;9(6):501-18.

14. Waugh RF. Academic staff perceptions of administrative quality at universities. Journal of Educational Administration. 2002.

15. Lalovic M. An ABET assessment model using Six Sigma methodology: University of Cincinnati; 2002.

16. Lagrosen S, Seyyed-Hashemi R, Leitner M. Examination of the dimensions of quality in higher education. Quality assurance in education. 2004.

17. Yang Z, Yan-ping L, Jie T, editors. Study on quality indicators in higher education: An application of the SERVQUAL Instrument. 2006 International Conference on Service Systems and Service Management; 2006: IEEE.

18. Tsinidou M, Gerogiannis V, Fitsilis P. Evaluation of the factors that determine quality in higher education: an empirical study. Quality assurance in Education. 2010.

19. Noaman AY, Ragab AHM, Madbouly AI, Khedra AM, Fayoumi AG. Higher education quality assessment model: towards achieving educational quality standard. Studies in Higher Education. 2017;42(1):23-46.

20. Al-Jobuisihalil KI, Al-JobuisHasn HS. Evaluating the Experience of Open College of Education in Mosul City. College of Basic Education Researches Journal. 2007;6(3):87-112.

21. Muhammed MA. Evaluation of the performance and Quality of Learning Resources at the College 
of Tourism Sciences of Al- Mustansiriyah University -an Empirical Study. Gulf Economist. 2017;33(32):119-46.

22. Jasim SR. Measurement of Quality Costs to Administration and Economics College at University of Anbar and the Impact of Displacement on These Costs/Analytical Study For 2013-2017. Tikrit Journal of Administration and Economics Sciences. 2019;15(47 Part 1):1-20.

23. Dawood FS. leading quality of university education in accordance with the strategic planning. ALAnbar University journal of Economic and Administration Sciences. 2016;8(15):253-83.

24. Taher Hameed Abbas B. Evaluation of the Educational Service Quality from the Perspective of Students' Using the (HEdPERF) Model Field Study in the Al-Dewaniyah Technical Institute. Al Kut Journal of Economics Administrative

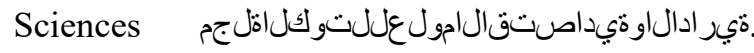
2019;1(31):134-61.

25. Parasuraman A, Zeithaml VA, Berry LL. A conceptual model of service quality and its implications for future research. Journal of marketing. 1985;49(4):41-50.

26. Abdullah F. Measuring service quality in higher education: HEdPERF versus SERVPERF. Marketing Intelligence \& Planning. 2006.

27. Abdullah F. The development of HEdPERF: a new measuring instrument of service quality for the higher education sector. International journal of consumer studies. 2006;30(6):569-81.

28. Sanders DR, Irwin SH. The impact of index funds in commodity futures markets: A systems approach. The Journal of Alternative Investments. 2011;14(1):40-9. 